[d002]
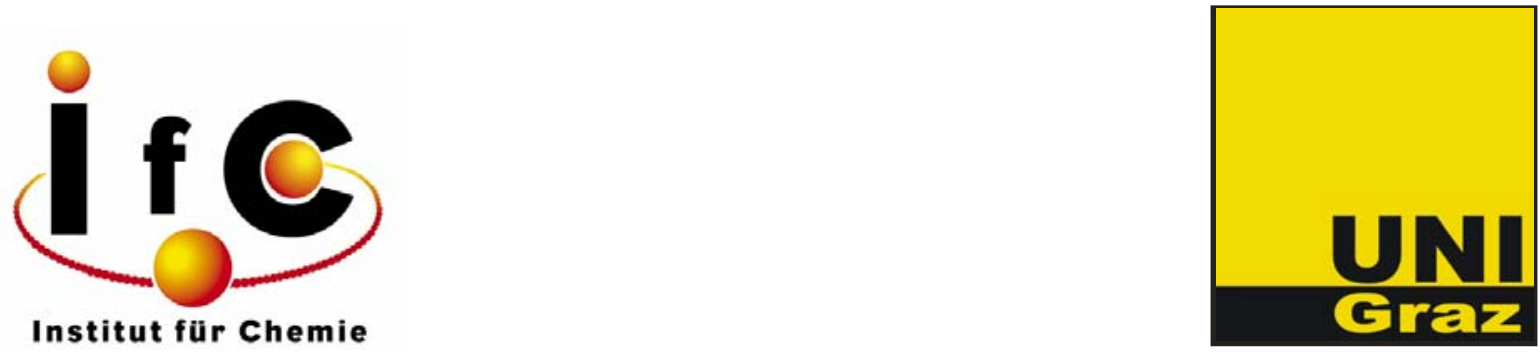

\title{
A Facile Lab Scale Synthesis of Red Selenium
}

Jörg Ebels, Stefan Spirk and Rudolf Pietschnig*

Institut für Chemie, Karl-Franzens-Universität Graz, Schubertstraße 1, A-8010 Graz, Austria, email: rudolf.pietschnig@uni-graz.at

\section{Introduction}

The reaction of organometallic compounds with elemental selenium is the most general synthetic route to organoselenium compounds. ${ }^{1-4}$ The reactivity of selenium towards less reactive metal-carbon bonds can be enhanced by using selenium transfer reagents such as selenophosphoranes $\mathrm{SePR}_{3}$ or selenocyanate $\mathrm{SeCN}^{-}$or simply the metastable red modification of selenium. ${ }^{5}$ The latter can be prepared by reduction of selenous acid with $\mathrm{SO}_{2}$ in the cold while at higher temperature grey selenium is formed. ${ }^{6}$ Since we found this well known procedure somewhat tedious for the preparation of red selenium on a small scale, we were interested in an alternative procedure to prepare the activated red form of selenium by taking advantage of a reaction sequence known for analytical purposes. ${ }^{7}$ The dissolution and reprecipitation of selenium from sulfuric acid is a simple procedure which should be useful for anybody who requires small quantities of red selenium for selenation reactions. 


\section{Results and Discussion}

Small quantities of red selenium can be readily prepared by reacting grey selenium with concentrated sulfuric acid at elevated temperature. The selenium dissolves under formation of a greenish dark solution. The thus obtained mixture is poured on crushed ice upon which red selenium precipitates. The product is collected by filtration and is subsequently washed with water until the filtrate shows a neutral $\mathrm{pH}$ value. Then the wet product is washed with ethanol and finally ether. After drying in vacuo the product is ready for use in further reactions.

The chemistry behind this conversion of grey to red selenium can be easily understood according to the following reaction sequence. In the initial step grey selenium is oxidized by sulfuric acid forming the well known $\mathrm{Se}_{8}{ }^{2+}$ cation (Scheme 1) which exhibits a green colour.

$$
\mathrm{Se}_{\text {grey }}+\mathrm{H}_{2} \mathrm{SO}_{4} \rightarrow \mathrm{Se}_{8}^{2+}+2 \mathrm{HSO}_{4}^{-}+2 \mathrm{H}_{2} \mathrm{O}+\mathrm{SO}_{2}
$$

Scheme 1: Oxidation of grey selenium.

On quenching with ice the $\mathrm{Se}_{8}{ }^{2+}$ cation can get reduced by $\mathrm{SO}_{2}$ still present in the solution or undergo disproportionation according to the following equations:

$$
\begin{aligned}
& \mathrm{Se}_{8}{ }^{2+}+\mathrm{SO}_{2}+2 \mathrm{H}_{2} \mathrm{O} \rightarrow \mathrm{Se}_{8(\mathrm{red})}+\mathrm{H}_{2} \mathrm{SO}_{4}+2 \mathrm{H}^{+} \\
& 8 \mathrm{Se}_{8}{ }^{2+}+8 \mathrm{H}_{2} \mathrm{O} \rightarrow 7 \mathrm{Se}_{8(\mathrm{red})}+8 \mathrm{H}_{2} \mathrm{SeO}_{3}+16 \mathrm{H}^{+}
\end{aligned}
$$

Scheme 2: Reduction and disproportionation of $\mathrm{Se}_{8}{ }^{2+}$ to red selenium.

Besides diluting the sulfuric acid, the use of crushed ice avoids elevated temperatures during the precipitation process which prevents the conversion of the red into the grey selenium modification. All byproducts formed in the precipitation step are water soluble and are therefore easily removed from the product by filtration and subsequent washing with water. 

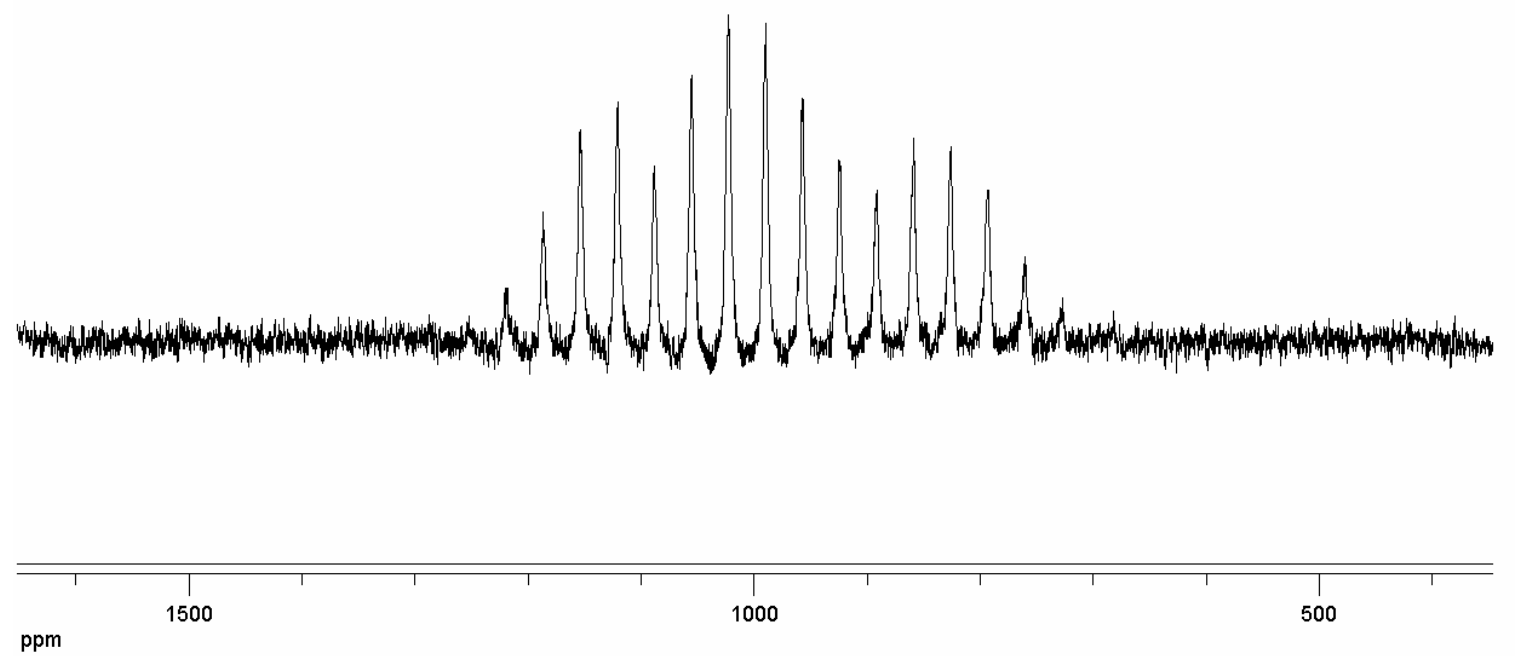

Figure 1: ${ }^{77}$ Se solid state NMR spectrum of elemental selenium (rotation frequency $2.5 \mathrm{kHz}$ ).

\section{Experimental}

$100 \mathrm{~mL}$ of concentrated sulfuric acid are heated to $150^{\circ} \mathrm{C} .1 \mathrm{~g}$ of grey selenium is added in portions while stirring. Heating is continued for a short while, after which the solution shows a dark green color. The mixture is poured on approximately $200 \mathrm{~mL}$ of crushed ice which causes a red precipitate of selenium. Once the ice has melted completely, the mixture is filtered and washed with water until the filtrate is neutral. For faster drying the raw product is then washed with ethanol and later diethyl ether. The product is collected and dried in vacuum without heating.

\section{Solid-State-NMR}

Solid state NMR spectra were recorded at $22^{\circ} \mathrm{C}$ on a Bruker DSX 400 spectrometer at 76,3 $\mathrm{MHz}\left({ }^{77} \mathrm{Se}\right.$ ) with bottom layer rotors of $\mathrm{ZrO}_{2}$ (diameter $4 \mathrm{~mm}$ ) containing ca. $75 \mathrm{mg}$ of sample, using a rotation frequency of $2.5 \mathrm{kHz}$

\section{Acknowledgements}

We acknowledge the Austrian Science Fund (FWF) for financial support (project P17882N11). 


\section{References:}

(1) Rheinboldt, H. In Houben-Weyl, 1955, p 961-969.

(2) Brandsma, L., Preparative Acetylenic Chemistry; Elsevier, 1988.

(3) Pietschnig, R.; Merz, K.; Schäfer, S., Heteroatom Chem. 2005, 16 (2), 169.

(4) Pietschnig, R.; Schäfer, S.; Merz, K., Org. Lett. 2003, 5, 1867-1869.

(5) P. Nicpon, D. W. Meek, Inorg. Chem. 1966, 5, 1297.

(6) Hollemann, Wiberg, Lehrbuch der Anorganischen Chemie, W. de Gruyter, Berlin.

(7) Jander, Blasius, Lehrbuch der analytischen und präparativen anorganischen Chemie, Hirzel-Verlag, Stuttgart. 